\title{
Effect of 5 Weeks of Isometric Handgrip Training on the Resting Blood Pressure in Young Healthy Individuals
}

\author{
Sumedha Shamsunder Audi ${ }^{1}$, Isabelle Coelho Correia Afonso ${ }^{2}$, Yogesh Parshuram Nerkar ${ }^{3}$ \\ 1, 2,3 Department of Physiology, Goa Medical College, Goa, India.
}

\section{ABSTRACT}

\section{BACKGROUND}

Urbanization and modern lifestyle pattern have resulted in mechanization of life and rise in the diseases such as hypertension that are associated with sedentary lifestyle. Regular physical exercise has many health benefits and is an essential part of a healthy lifestyle. Our aim was to study the effect of 5 weeks of Isometric Handgrip Training (IHT) on the resting Blood Pressure (BP) in young healthy individuals.

\section{METHODS}

The study was conducted among 46 apparently healthy medical students of both genders, in the age group of 18 to 21 years. Resting BP was recorded before starting IHT and again on completion of IHT after 5 weeks. IHT was performed with the dominant hand, using handgrip spring dynamometer (Fig 1). Each IHT session, consisted of five sets of 2 minutes isometric contractions, at $30 \%$ of the Maximum Voluntary Contraction (MVC) force with 3 minutes rest after each contraction. The exercise training sessions were conducted thrice a week for 5 weeks.

\section{RESULTS}

Data obtained from 46 healthy male and female students was analysed. Paired ' $\mathrm{T}$ ' test was used for comparison of mean values of Systolic BP (SBP), Diastolic BP (DBP) and Mean Arterial BP (MAP) before and after isometric handgrip training. P value of less than 0.05 was accepted as indicating significant difference between the compared values. We found that isometric handgrip training of 5 weeks produced significant decrease in the mean values of SBP, DBP and MAP in our subjects. (Table 1, Figure 2).

\section{CONCLUSIONS}

Our subjects performed 3 sessions per week of unilateral IHT at $30 \%$ MVC consisting of five sets of 2 minutes contractions separated by 3 minutes rest. It was found that after 5 weeks of training, there was significant decrease in resting SBP, DBP and MAP in our subjects.

\section{KEY WORDS}

Isometric Handgrip Training, Handgrip Dynamometer, Resting Blood Pressure
Corresponding Author:

Dr. Sumedha Shamsunder Audi.

Department of Physiology,

Goa Medical College, Bambolim,

Goa, India.

E-mail: audisumedha@gmail.com

DOI: $10.14260 /$ jemds/2021/30

How to Cite This Article:

Audi SS, Afonso ICC, Nerkar YP. Effect of 5 weeks of isometric handgrip training on the resting blood pressure in young healthy individuals. J Evolution Med Dent Sci 2021;10(03):143-147, DOI: 10.14260/jemds/2021/30

Submission 22-09-2020,

Peer Review 17-11-2020,

Acceptance24-11-2020

Published 18-01-2021.

Copyright (C) 2021 Sumedha Shamsunder Audi et al. This is an open access article distributed under Creative Commons Attribution License [Attribution 4.0 International (CC BY 4.0)] 


\section{BACKGROUND}

Diseases such as hypertension can develop at a much younger age as a result of sedentarism, unhealthy diets, and increased mental stress. Arterial BP equal to or more than 140 / $90 \mathrm{~mm}$ $\mathrm{Hg}$ is defined as arterial hypertension. ${ }^{1}$ Risk of cardiovascular complications increase logarithmically with rising levels of systolic blood pressure at or above $115 \mathrm{~mm} \mathrm{Hg}$ and diastolic blood pressure at or above $75 \mathrm{~mm} \mathrm{Hg.}{ }^{1}$ Incorporating healthpromoting lifestyles, healthy diets and regular physical exercises in daily routine, may prevent development of hypertension later in life. ${ }^{2}$ Either isotonic exercises or isometric exercises or combination of both types of exercises can be performed. In isotonic skeletal muscle exercises, the muscle length changes and the muscle tension remains constant. ${ }^{3}$ Isotonic exercises in form of aerobics have shown to have a favourable effect on blood pressure. ${ }^{2}$ But due to time constraints, busy individuals very often refuse to take up these exercises and adherence to these exercises is poor. Isometric skeletal muscle exercises consist of sustained contraction of the skeletal muscle against an immovable load or resistance. Shortening of the skeletal muscle is prevented so the muscle remains at constant length despite increasing tension. ${ }^{3}$ Metaanalyses indicated that decrease in BP achieved with isometric handgrip exercise training may be similar or even greater than $\mathrm{BP}$ reductions obtained with dynamic aerobic and resistance type of exercises. ${ }^{4,5}$ Isometric handgrip exercise training may be also be helpful as an adjunct to drug therapy in hypertensives. $5,6,7,8$

Very often the students pursuing higher studies in professional colleges are under constant stress due to busy academic schedules. They cannot make time for outdoor games or dynamic physical exercises such as walking, jogging, and swimming. Physical inactivity and stress are risk factors for hypertension. Regular physical exercises help in reducing BP and also decrease risk of cardiovascular diseases. ${ }^{2}$ Young busy students in professional colleges need simple, short duration exercises that can be performed anywhere, anytime and even while studying. IHT can be performed in a sitting or standing position even whilst studying, with the help of a handy, portable, simple to use and affordable handgrip dynamometer. IHT are time saving exercises, well tolerated and no adverse effects have been reported.5,9 Hence there are more chances of greater compliance to these types of exercises. 4,6 The aim of the present work was to study effect of 5 weeks of isometric handgrip training on the resting BP in young healthy individuals.

\section{METHODS}

This prospective pre-test post-test study was conducted among 46 healthy male and female medical students in the age group of 18 - 21 years. The subjects were randomly selected from $1{ }^{\text {st }}$ MBBS medical students of our college. After explaining the procedure of the isometric handgrip exercise training, informed consent was taken from the participants. The required sample size for this study was calculated as 46 using the formula. ${ }^{10}$

$$
\mathrm{N}=2 \times\left(\mathrm{Z}_{\alpha}+\mathrm{Z}_{\beta}\right)^{2} \times \sigma_{1}^{2}+\sigma_{2}^{2} /\left(\mu_{1}-\mu_{2}\right)^{2}
$$

The assumptions were $\alpha=5 \%$ Therefore $Z_{\alpha}=1.96, \beta=80 \%$ Therefore $Z_{\beta}=0.84, \sigma_{1}=6.86$ and $\sigma_{2}=7.96, \mu_{1}=120.44$ and $\mu_{2}$ $=114.29$. Confidence interval of $95 \%$. The $\mathrm{T}$ test was two tailed and effect size was 0.6. Response variable approximates to a normal distribution. Mean $(\mu)$ standard deviation $(\sigma)$ were taken from a similar study by Prashanth et al. ${ }^{11}$

\section{Inclusion and Exclusion Criteria}

Subjects BP was recorded, and clinical examinations was done and the normotensive subjects with no history of cardiovascular disease or kidney disease were included in this study. The participants were non-smokers, non-alcoholics, were not on any medications and were not engaged in any regular exercise routine or walking, jogging, yoga, and pranayama. The subjects having a hand deformity, or any history of inflammatory joint disorder, fracture or any muscular or neurological disorder of upper limb were excluded from the present study.

\section{Instruments}

The isometric exercise training was performed with the help of a handgrip spring dynamometer (Inco, Ambala). It has two handles connected through a flexible metallic strip. It has graduated scale for estimation of compression force.

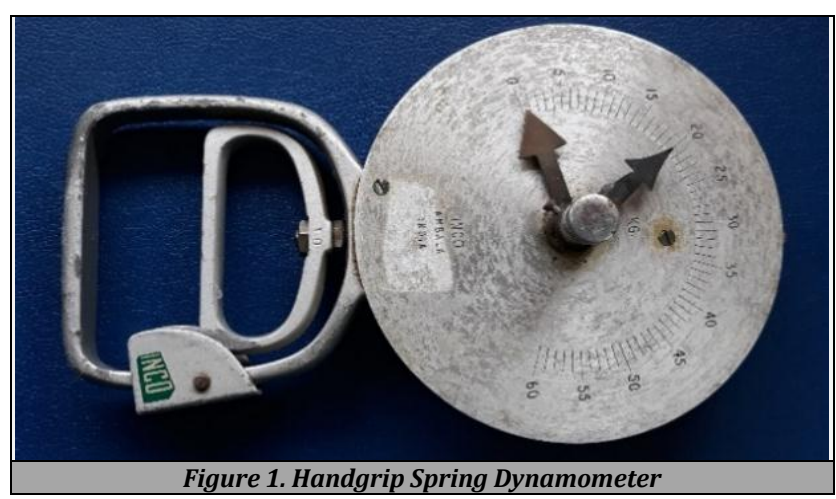

BP was measured with help of a mercury sphygmomanometer and stethoscope.

\section{BP Measurement}

Resting BP of the subject was recorded before the start of isometric handgrip exercise training. Isometric handgrip training was given for 5 weeks and BP of the subject was recorded again after 5 weeks of IHT training

\section{Measurement of Resting BP}

The subjects were allowed to rest comfortably for 10 minutes before recording the resting BP. At the time of BP recording, the subjects were instructed to breathe normally and avoid breath holding to prevent the influence of Valsalva manoeuvre on BP. Three recordings of resting BP were taken with a gap of two minutes between each of the readings. Average values of 3 readings each of resting SBP and resting DBP were used for statistical analyses. After the resting BP was recorded, the subjects were asked to relax for 5 minutes before recording MVC. 


\section{Determination of Maximum Voluntary Contraction}

The subjects were asked to press the handle of the handgrip dynamometer with the dominant hand briefly for about $2-3$ seconds with maximum effort and the value of maximum voluntary contraction was noted. The subjects were given 3 attempts with a gap of 1 minutes between each attempt. The highest value of the 3 attempts obtained on the handgrip dynamometer was recorded as MVC. The subjects were asked to rest for 5 minutes before starting exercise training.

\section{Isometric Handgrip Training}

The subjects were instructed to perform isometric handgrip exercise training with the dominant hand for 5 weeks. Isometric handgrip training consisted of five sets of 2 minutes isometric contractions at $30 \% \mathrm{MVC}$, with a rest of 3 minutes after each contraction. This supervised IHT protocol was conducted 3 times per week for a total period of five weeks.

\section{Measurements of $B P$ after Training}

After completing 5 weeks of isometric exercise training, again three recordings of BP were taken with a gap of two minutes after each of the readings. Average values of 3 readings each of SBP and DBP obtained after IHT were used for statistical analysis. Pulse pressure (PP) and mean arterial pressure (MAP) was calculated using the formulas ${ }^{12} \quad \mathrm{PP}=\mathrm{SBP}-\mathrm{DBP}$ and $\mathrm{MAP}=\mathrm{DBP}+1 / 3(\mathrm{PP})$.

\section{Statistical Analysis}

Statistically analysis was done using SPSS Software Version 27. Data of 46 healthy male and female medical students was collected. The mean values of SBP, DBP, MAP obtained before and after 5 weeks of isometric handgrip training, were expressed as Mean + SD. Data was analysed using Paired " $\mathrm{T}$ " Test and $95 \%$ confidence interval of difference and $p$ value of $<0.05$ was taken as statistically significant.

\section{RESULTS}

\begin{tabular}{|c|c|c|c|c|}
\hline BP (mm Hg) & Mean \pm SD & T Value & df & P Value \\
\hline SBP before IHT & $114.43 \pm 5.89$ & \multirow{2}{*}{12.04} & \multirow{2}{*}{45} & \multirow{2}{*}{$<0.001$} \\
\hline SBP after IHT & $106.39 \pm 5.07$ & & & \\
\hline DBP before IHT & $73.83 \pm 5.61$ & \multirow{2}{*}{7.06} & \multirow{2}{*}{45} & \multirow{2}{*}{$<0.001$} \\
\hline DBP after IHT & $68.70 \pm 5.12$ & & & \\
\hline MAP before IHT & $87.36 \pm 4.73$ & \multirow{2}{*}{9.58} & \multirow{2}{*}{45} & \multirow{2}{*}{$<0.001$} \\
\hline MAP after IHT & $81.78 \pm 4.64$ & & & \\
\hline $\begin{array}{r}\text { Table 1. Sho } \\
\text { and }\end{array}$ & $\begin{array}{l}\text { Effect of } 5 \\
\text { mHg) Expr }\end{array}$ & $\begin{array}{l}\text { is of II } \\
\text { as } M e\end{array}$ & DE & BP, \\
\hline
\end{tabular}

After 5 weeks of supervised IHT, we found that there was a significant decrease in SBP, DBP, and MAP in our subjects. Resting mean \pm SD SBP was $114.43 \pm 5.89 \mathrm{~mm} \mathrm{Hg}$ and after 5 weeks of IHT mean \pm SD SBP was $106.39 \pm 5.07 \mathrm{~mm} \mathrm{Hg} \mathrm{(p<}$ 0.001). Resting mean \pm SD DBP was $73.83 \pm 5.61 \mathrm{~mm} \mathrm{Hg}$ and after 5 weeks of IHT mean DBP \pm SD was $68.70 \pm 5.12 \mathrm{~mm} \mathrm{Hg}$ $(\mathrm{p}<0.001)$. Before IHT mean \pm SD MAP was $87.36 \pm 4.73 \mathrm{~mm}$ $\mathrm{Hg}$ and after 5 weeks of IHT mean MAP \pm SD was $81.78 \pm 4.64$ $\mathrm{mm} \mathrm{Hg}(\mathrm{p}<0.001)$ (Table 1$)$. The graph shows comparison of mean SBP, mean DBP and mean MAP before and after IHT (Figure 2)

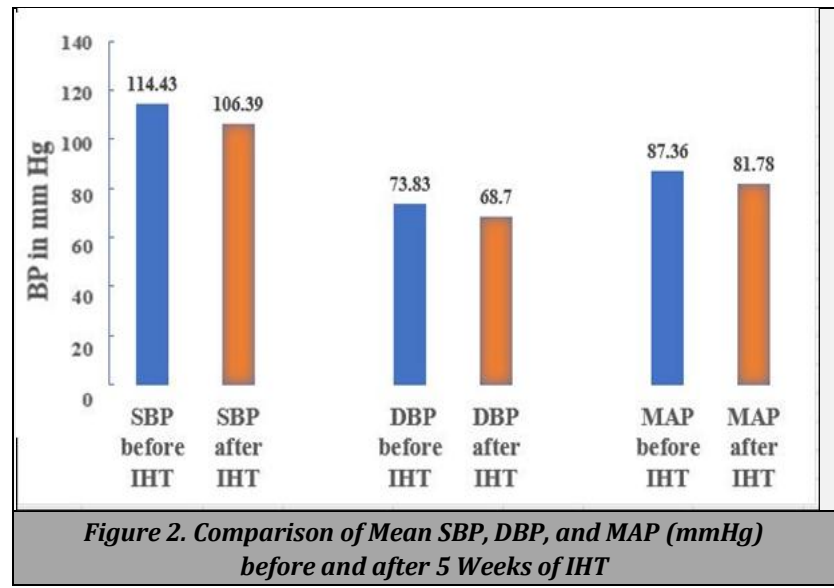

\section{DISCUSSION}

We studied the effect of unilateral IHT conducted at $30 \%$ MVC thrice a week over a period of 5 weeks in 46 young healthy medical students. In our study we found a significant reduction in resting $\mathrm{BP}$ in the subjects after 5 weeks of isometric exercise training. The mean values of SBP, DBP and MAP showed significant decrease after 5 weeks of IHT. The results of our study were similar to that of Prashant $\mathrm{P}$ et al who found significant decrease in the resting BP in healthy normotensive medical students trained for 5 weeks compared to an untrained control group. ${ }^{11}$ Our results are consistent with that of Garg et al who reported significant reductions in resting SBP and DBP in young healthy adults trained for 10 weeks. ${ }^{13}$ Various other studies also have reported that isometric exercise training was effective in lowering resting $\mathrm{BP}$ in their subjects. 14,15,16,17,18,19

Over the years various researchers have evaluated mechanisms that could be responsible for BP reduction in response to isometric handgrip exercise training, but the exact cause is not yet clear. Cardiac output and peripheral resistance are the determinants of arterial BP,12 hence BP lowering effect of isometric handgrip training possibly involves multiple mechanisms. ${ }^{20}$ Individuals who suffer from hypertension before age of 50 years usually have an increase in systolic as well as diastolic BP and the fault is vasoconstriction at the resistance vessels. ${ }^{1}$ Nitric oxide synthase enzyme in the vascular endothelium synthesizes nitric oxide, a potent vasodilator and dilation of the resistance vessels decreases BP. ${ }^{21}$ This endothelium dependent, nitric oxide mediated vasodilation is often defective in the hypertensives. ${ }^{1}$ Shear stress is a factor that increases bioavailability of nitric oxide by activating nitric oxide synthase enzyme. ${ }^{21}$ IHT increases shear stress as repeated isometric efforts with rest pauses during training repeatedly occludes vascular lumen, increases sympathetic activity and increases blood flow. ${ }^{22}$ Various studies have shown that handgrip exercise training has a favorable influence on the vascular endothelium and local, nitric oxide dependent vasodilation is better after training. 16,17,23,24 But in one study on the normotensive subjects by McGowan CL et al, IHT lowered resting BP but it did not improve function of the systemic vascular 
endothelium. ${ }^{19}$ Improved vascular endothelial function and more bioavailability of nitric oxide can also occur when the oxidative stress is reduced. Increased oxidative stress reduces bioavailability of nitric oxide because excess reactive oxygen species inactivates nitric oxide. Peters et al reported that exercise training increases antioxidant agents. Authors attributed BP reduction in their subjects to exercise training induced decrease in the oxidative stress. ${ }^{25}$

Inder et al indicated that the mechanism for BP response to IHT may be mediated by the metabolites produced during training. The authors suggested that the metabolites formed during repeated hypoxia occurring due to repeated vessel occlusion during IHT, possibly might act as a stimulus for BP reduction. ${ }^{5}$ Another study reported that the training induced increased muscle blood flow and aerobic metabolism reduces the concentration of the metabolites in the muscle interstitial tissue. This results in less stimulation of muscle chemoreceptor afferent nerve endings and hence decreases metaboreceptors mediated rise in BP. ${ }^{26}$ Researchers have also investigated if other mechanisms such as changes in autonomic functions, 18,27,28,29,30 or increase in muscle blood flow $^{31}$ could be the mediators of BP reduction occurring after exercise training.

We have not investigated the mechanisms responsible for lowering BP after isometric exercise training hence we cannot comment on the cause of the reduction in the resting BP in our subjects following 5 weeks IHT. Study of the mechanisms for BP lowering effect of IHT would have enriched our study.

\section{CONCLUSIONS}

5 weeks of IHT was effective in lowering resting BP in our young healthy subjects. There were significant reductions in resting SBP, DBP and MAP. IHT can be performed anywhere, be it at home, hostel, at the college during free time or even whilst reading or studying. Hence IHT is a very convenient type of exercise for busy students in professional colleges who very often fail to show compliance to dynamic aerobic or resistance exercises.

Data sharing statement provided by the authors is available with the full text of this article at jemds.com.

Financial or other competing interests: None.

Disclosure forms provided by the authors are available with the full text of this article at jemds.com.

\section{REFERENCES}

[1] Goldman L, Ausiello D. Goldman's cecil medicine. Vol. 1. 23rd edn. Elsevier 2007:430-3.

[2] Longo DL, Fauci AS, Kasper DL, et al. Harrison's principles of internal medicine. Vol. 2. 18 th edn. McGraw-Hill 2012: p. 2054.

[3] Hall JE. Guyton and Hall textbook of medical physilogy. $12^{\text {th }}$ edn. Elsevier 2010: p. 79.

[4] Owen A, Wiles J, Swaine I. Effect of isometric exercise on resting blood pressure: a meta-analysis. J Hum Hypertens 2010;24(12):796-800
[5] Inder JD, Carlson DJ, Dieberg G, et al. Isometric exercise training for blood pressure management: a systematic review and meta-analysis to optimize benefits. Hypertens Res 2016;39(2):88-94.

[6] Smart NA, Way D, Carlson D, et al. Effects of isometric resistance training on resting blood pressure: individual participant data meta-analysis. J Hypertens 2019;37(10):1927-38.

[7] Piikmann S, Reisberg K. The effect of isometric handgrip training on blood pressure. Acta Kinesiologiae Universitatis Tartuensis 2018;24:109-20.

[8] Farah BQ, Germano-Soares AH, Rodrigues SLC, et al. Acute and chronic effects of isometric handgrip exercise on cardiovascular variables in hypertensive patients: a systematic review. Sports (Basel) 2017:5(3):55.

[9] De Araujo CGS, Duarte CV, Gonçalves, FDA et al. Hemodynamic responses to an isometric handgrip training protocol. Arq Bras Cardiol 2011;97(5):413-9.

[10] Parikh MN, Hazra A, Mukherjee J, et al. Research methodology simplified every clinician a researcher. 1st edn. New Delhi: Jaypee Brothers Medical Publishers 2010: $\mathrm{p} 103$

[11] Prashant P, Shankarappa V, Malhotra V, et al. Cardiovascular responses to isometric handgrip training in normotensive medical students. International Journal of Current Research \& Review 2012:4(4):105-10.

[12] Jain AK. Textbook of physiology. Vol. 1. $8^{\text {th }}$ edn. Avichal Publishing Company 2019:345-6.

[13] Garg R, Malhotra V, Kumar A, et al. Effect of isometric handgrip exercise training on resting blood pressure in normal healthy adults. J Clin Diagn Res 2014;8(9):BC0810.

[14] Millar PJ, Bray SR, MacDonald MJ, et al. The hypotensive effects of isometric handgrip training using an inexpensive spring handgrip training device. J Cardiopulm Rehabil Prev 2008;28(3):203-7.

[15] Wiley RL, Dunn CL, Cox RH, et al. Isometric exercise training lowers resting blood pressure. Med Sci Sports Exerc 1992;24(7):749-54.

[16] Badrov MB, Bartol CL, DiBartolomeo MA, et al. Effect of isometric handgrip training dose on resting blood pressure and resistance vessel endothelial function in normotensive women. Eur J Appl Physiol 2013;113(8):2091-100.

[17] Badrov MB, Freeman SR, Zokvik MA, et al. Isometric exercise training lowers resting blood pressure and improves local brachial artery flow - mediated dilation equally in men and women. Eur J Appl Physiol 2016;116(7):1289-96.

[18] Ray CA, Carrasco DI. Isometric handgrip training reduces arterial pressure at rest without changes in sympathetic nerve activity. Am J Physiol Heart Circ Physiol 2000;279(1):H245-9.

[19] McGowan CL, Levy AS, McCartney N, et al. Isometric handgrip training does not improve flow mediated dilation in subjects with normal blood pressure. Clin Sci (Lond) 2007;112(7):403-9.

[20] Millar PJ, McGowan CL, Cornelissen VA, et al. Evidence for the role of isometric exercise training in reducing blood pressure: potential mechanisms and future directions. Sports Med 2014;44(3):345-56.

[21] Barett KE, Barman SM, Boitano S, et al. Ganong's review of medical physiology. 25 ${ }^{\text {th }}$ edn. McGraw-Hill 2016:594-5. 
[22] Batman BA, Hardy JC, Leuenberger U, et al. Sympathetic nerve activity during prolonged rhythmic forearm exercise. J Appl Physiol 1994;76(3):1077-81.

[23] McGowan CL, Visocchi A, Faulkner M, et al. Isometric handgrip training improves local flow- mediated dilation in medicated hypertensives. Eur J Appl Physiol 2007;99(3):227-34.

[24] McGowan CL, Levy AS, Millar PJ, et al. Acute vascular responses to isometric handgrip exercise and effects of training in persons medicated for hypertension. Am J Physiol Heart Circ Physiol 2006;291(4):H1797-802.

[25] Peters PG, Alessio HM, Hagerman AE, et al. Short-term isometric exercise reduces systolic blood pressure in hypertensive adults: Possible role of reactive oxygen species. Int J Cardiol 2006;110(2):199-205.

[26] Mostoufi-Moab S, Widmaier EJ, Cornett JA, et al. Forearm training reduces the exercise pressor reflex during ischemic rhythmic handgrip. J Appl Physiol 1998;84(1):1277-83.
[27] Millar PJ, Levy AS, McGowan CL, et al. Isometric handgrip training lowers blood pressure and increases heart rate complexity in medicated hypertensive patients. Scand J Med Sci Sports 2013;23(5);620-6.

[28] Taylor AC, McCartney N, Kamath MV, et al. Isometric training lowers resting blood pressure and modulates autonomic control. Med Sci Sports Exerc 2003;35(2):2516.

[29] Somers V, Leo KC, Shields R, et al. Forearm endurance training attenuates sympathetic nerve response to isometric handgrip in normal humans. J Appl Physiol 1992;72(3):1039-43.

[30] Sinoway L, Shenberger J, Leaman G, et al. Forearm training attenuates sympathetic responses to prolonged rhythmic forearm exercise. J Appl Physiol 1996:81(4):1778-84.

[31] Sinoway L, Shenberger J, Wilson D, et al. A 30-day forearm work protocol increases maximal forearm blood flow. J Appl Physiol 1987;62(3):1063-7. 